\title{
A STUDY ON MECHANICAL, TRIBOLOGICAL AND BIOLOGICAL CHARACTERISTICS OF TITANIUM HYDROXYAPATITE (Ti-HA) IMPLANTS
}

\author{
B. Pranesh ${ }^{\# 1}$, Dilish.K. Das ${ }^{\# 2}$, S. Dhinesh Balaji ${ }^{\# 3}$ and K. Ramesh Kumar ${ }^{\# 4}$ \\ \#1 Associate Professor, Sri Ramakrishna Engineering College \\ \#2 Sri Ramakrishna Engineering College \\ \#3 Sri Ramakrishna Engineering College \\ \#4 Sri Ramakrishna Engineering College
}

\section{ABSTRACT}

The field of biomaterials has become a vital area, as these materials can improve the quality and longevity of human life. This paper discusses the mechanical, structural, chemical and biomechanical characteristics of Titanium(Ti) and Hydroxyapatite Coated Titanium materials. This brings out the overall superiority of Ti based alloys, even though it is costlier. As it is well known that a good biomaterial should possess the fundamental properties such as better mechanical and biological compatibility, enhanced wear and corrosion resistance in biological environment. Hence a material with excellent combination of high strength and low modulus closer to bone has to be used for implantation to avoid loosening of implants and higher service period to avoid revision surgery. This can be achieved by Ti and Ti-HA implants to a greater extent. Ti implants possess should possess the fundamental properties such as better mechanical and biological compatibility, enhanced wear and corrosion resistance in biological environment. Along with HA coating, it acquires biocompatibility and bioactivity. Hence it remains an excellent selection of Bio-implant material. This paper in overall elucidates the superiority of Ti and HA-Ti implant materials by studying the performance factors, coating methodologies, structural characteristics, electrochemical analysis and in vitro biological tests.

KEYWORDS:Hydroxyapatite, Corrosion, Biocompatibility, Spectroscopy, Cytotoxicity.

\section{Corresponding author: B. Pranesh}

\section{INTRODUCTION}

The demand for medical implants in humans is increasing rapidly each year due to the loss of body functions caused by the aging process and accidents. Over the past 20 years, titanium (Ti) and its alloys have been used as implant materials owing to their good corrosion resistance and biocompatibility based on their chemical and mechanical properties [1]. Titanium alloys are attractive metallic materials for biomedical applications because of its excellent mechanical, physical 
and biological performance. Ti-6Al-4V (ASTM F136) is an alpha-beta alloy, the microstructure, mechanical behaviour and chemical stability of which depend upon the type of heat treatment and mechanical working. This alloy is good for biomedical applications. These alloys must have high strength and a long fatigue life (i.e.,) high fatigue strength. The Young's modulus and tensile strength, ductility, fatigue life, fretting fatigue life, wear properties, functionalities, etc., should be controlled so that their levels are suitable for structural biomaterials used in implants that replace hard tissue. For the long-term usage of metallic implants, mechanical biocompatibilities should be enhanced. Being bioinert metallic materials, however, they cannot bond directly to living bone after implantation into a host body [2]. Therefore, for the successful application of titanium materials in implants, a surface treatment process to enhance contact with bone and increase the bioactivity within the body must be developed. To accomplish this, various surface treatments, such as coating hydroxyapatite (HA) powder onto the titanium surface by plasma-spray, implantation of calcium ions into the implant surface using an ion beam and treating with an electrolyte solution containing alkaline metal ions, have received considerable attention.

\subsection{REQUIREMENTS OF A BIOMATERIAL}

The requirement of the biomaterial is its acceptability by the human body. The implanted material should not cause any adverse effects like allergy, inflammation and toxicity either immediately after surgery or under post-operative conditions. Next to that, biomaterials should possess sufficient mechanical strength to sustain the forces to which they are subjected so that they do not undergo fracture and more importantly, a bioimplant should have very high corrosion and wear resistance in highly corrosive body environment and varying loading conditions, apart from fatigue strength and fracture toughness. This requirement obviously demands a minimum service period of from 15 to 20 years in older patients and more than 20 years for younger patients. The success of a biomaterial or an implant is highly dependent on three major factors (i) the properties (mechanical, chemical and tribological) of the biomaterial in question (ii) biocompatibility of the implant and (iii) the health condition of the recipient and the competency of the surgeon. The currently used materials that were selected based on above mentioned criteria though function well in the human system are still found to generally fail within a period of about 12-15 years, which leads to revision surgery in order to regain the functionality of the system.

\subsection{TITANIUM AND ITS ALLOYS}

Commercially pure titanium (Ti-CP) and extra low interstitial Ti-6Al-4V are most commonly used titanium base implant biomaterials. These materials are classified as biologically inert biomaterials. As such, they remain essentially unchanged when implanted into human bodies. However, they do not promote any adverse reactions and are tolerated well by the human tissues. Titanium is very light with a density of $4.5 \mathrm{~g} / \mathrm{cm}^{3}$. Pure Ti is an allotropic metal having hexagonal $\alpha$-phase (HCP) and transforming to a cubic $\beta$-phase (BCC) over that temperature. It's very good biocompatibility is due the formation of an oxide film $\left(\mathrm{TiO}_{2}\right)$ over its surface. This oxide is a strong and stable layer that grows spontaneously in contact with air and prevents the diffusion of the oxygen from the environment providing corrosion resistance.Ti6Al4V alloy is widely used to manufacture implants and the addition of alloying elements to titanium enables it to have a wide range of properties because aluminium tends to stabilize the $\alpha$-phase and vanadium tends to stabilize $\beta$-phase, lowering the temperature of the transformation from $\alpha$ to $\beta$. The alpha phase promotes good weldability, excellent strength characteristics and oxidation resistance. The addition vanadium as a $\beta$ stabilizer causes the higher strength of beta-phase to persist below the transformation temperature which results in a two-phase system. The $\beta$-phase can precipitate by an ageing heat treatment. The modulus of elasticity of these materials is about $110 \mathrm{GPa}$. This is much lower than stainless steels and Co-base alloys modulus 210 and $240 \mathrm{GPa}$, respectively. (Davidson\& Gergette, 1986). 


\subsection{TITANIUM-HYDROXYAPATITE COMPOSITE}

Bio composite materials have been developed in order to combine bioactivity of ceramics and mechanical properties of metals. Hydroxyapatite (HA), is a naturally mineral form of calcium apatite with the formula $\mathrm{Ca}_{10}\left(\mathrm{PO}_{4}\right)_{6}(\mathrm{OH})_{2}$. Hydroxyapatite (HA) is weak and brittle but has an excellent biocompatibility and is a bioactive material. When HA is coated to titanium, a chemical property of the biomaterial occurs improves. New developments try to combine hydroxyapatite as a second phase to the Ti alloy. In this material, particles of HA are incorporated in a porous titanium matrix providing points of good bone reaction. It allows improved adhesion strength of the load bearing metallic component to the bone and results in shorter healing periods and also it has good behavior of the implant for longer periods of time.

Table.1 Hydroxyapatite properties

\begin{tabular}{|l|l|}
\hline Hardness (Mohs) & 5 \\
\hline Density $\left(\mathrm{g} / \mathrm{cm}^{3}\right)$ & 3.1 \\
\hline Elastic Modulus $(\mathrm{GPa})$ & 100 \\
\hline Ultimate Tension Stress $(\mathrm{MPa})$ & 100 \\
\hline Compression Stress $(\mathrm{MPa})$ & $>50(\mathrm{good})$ \\
\hline Toughness KIC $\left(\mathrm{MPa} \mathrm{m}{ }^{1 / 2}\right)$ & 1 \\
\hline Solubility & $\begin{array}{l}\text { It has the less solubility in body fluids media, so it is } \\
\text { impossible to have } \mathrm{Ca}^{2+} \text { or } \mathrm{PO}_{4}^{3+} \text { ions in water }(\mathrm{pH}=7)\end{array}$ \\
\hline
\end{tabular}

\subsection{PERFORMANCE FACTORS OF BIO-IMPLANTS MECHANICAL BEHAVIOR}

The yield strength, elastic modulus, tensile strength, ductility, fracture strength and toughness of a material can be determined by a simple tensile test. All of these parameters not only give valuable information to a design engineer, but also play an important role in deciding the long-term stability and biocompatibility of an implant material. A material with high elastic modulus may not be ideal for load bearing implants. This is because insufficient load transfer from an artificial implant to the adjacent remodelling bone may result in bone resorption and eventual loosening of the prosthetic device. Modulus of elasticity determines the stiffness of the material. Yield strength of a material determines the minimum stress necessary to produce plastic deformation. Hence, yield strength determines the ease at which a material can be deformed plastically into different shapes. Tensile strength gives an idea of the maximum load a material can withstand before failure. Ductility of a material indicates the extent to which a material can be deformed without fracture. Fracture strength determines the stress at which a material fails following necking after reaching the peak stress or the ultimate tensile strength. It occurs when the cohesive strength of a material is exceeded. This is an important parameter for designing hip implants as they are expected to withstand the loads during service without fracture. Toughness of a material may be defined as the area under the stressstrain curve. It determines the amount of work per unit volume that can be done on the material without rupture [3].

\section{CORROSION}

Corrosion is the deterioration of a material as a result of chemical and electrochemical reactions with its surrounding environment. Implant materials used inside a human body are generally exposed to a harsh aqueous environment containing various anions $\left(\mathrm{Cl}^{-}, \mathrm{HCO}^{3-}, \mathrm{HPO}_{4}{ }^{2-}\right)$, 
cations $\left(\mathrm{Na}^{+}, \mathrm{K}^{+,} \mathrm{Ca}^{2+}, \mathrm{Mg}^{2+}\right)$, organic substances, and dissolved oxygen. The metallic components of the alloy are initially oxidized to their ionic forms and release a free electron. The dissolved oxygen present in the aqueous environment then react with the water molecules and free electron to form hydroxyl ions. These hydroxyl anions then react with the metallic cations to form a corrosion product. The different types of corrosion that may take place on implant metallic materials are pitting, crevice, galvanic, intergranular, stress-corrosion cracking, corrosion fatigue, and fretting corrosion [3].

\section{SURFACE PROPERTIES}

When an implant material is inserted into the living tissue, an interface is created between the surface of the foreign implant material and the surrounding tissues. The surrounding tissue consists of water molecules, oxygen, negative and positive ions, proteins, and other biomolecules which may further built into larger structures such as cells and cell membranes. The biomaterial surfaces with different surface morphology, surface chemistry, and surface wettability may strongly influence the cell interaction and thereby tissue integration at the defect sites [3].

\section{SURFACE MORPHOLOGY}

It is well established that morphological features such as surface roughness and its topography can strongly influence the protein adsorption, cell attachment, cell proliferation, contact guidance, and differentiation. The surface roughness or its topography can be characterized by atomic force microscopy (AFM), mechanical stylus profilometry, SEM, laser profilometry, and confocal laser scanning microscopy [4].

\section{SURFACE WETTABILITY}

When an implant material is placed inside a human body, the first and the foremost event takes place is the wetting of the implant material by the physiological fluids. This further controls the adsorption of proteins followed by attachment of cells to the implant surface. The three most important factors that affect the wettability of a surface are its chemical composition, microstructural topography, and surface charge. Contact angle measurements are probably the most adopted technique to measure the average wettability of a surface [4].

\section{LITERATURE REVIEW}

\subsection{Preparation Methods}

Mechanical alloying and powder metallurgical process

The titanium-hydroxyapatite nanocomposite materials with different contents of HA were prepared by powder metallurgical process and mechanical alloying. The materials used were titanium (99\%) from Alfa Aesar and hydroxyapatite (reagent grade) powder from Sigma-Aldrich. Mechanical alloying was performed under argon atmosphere using a SPEX 8000 Mixer Mill. The vial was loaded and unloaded in Labmaster 130 glove box in high purity argon atmosphere. The mixed powders were first blended by mechanical alloying process with hard steel balls for $44 \mathrm{~h}$ and then uniaxially pressed at compacting pressure of 600MPa. The typical dimensions of the pellets were $\mathrm{d}=10 \mathrm{~mm}$ in diameter and $\mathrm{h}=3 \mathrm{~mm}$ in height. Finally, the green compacts were heat treated at $1150^{\circ} \mathrm{C}$ for $2 \mathrm{~h}$ under an argon atmosphere (99.999\% purity) to form ordered phases.[5]

\section{HA Preparation processes}

The bioactive surface treatment processes are, in general, classified as dry processes and wet processes. There are various dry and wet processes. The dry processes are further classified as direct HApreparation methods and indirect HA preparation methods. The examples of the former methods 
are the plasma spray method, ion plating, RF magnetron sputtering, pulse laser deposition method is some of the methods for coating HA directly on the titanium alloy surface. Examples of the latter methods are calcium ion implantation, in which calcium ions are implanted into biomedical titanium alloys; the calcium ion mixing method, in which $\mathrm{Ca}$ is sputtered on the surface of biomedical titanium alloys followed by Ar ion implantation; etc. When biomedical titanium alloys from these preparation methods are implanted into a living body, $\mathrm{CaP}$ precipitation is enhanced on the surface. Wet processes are, for example, electrical chemical treatment, in which the biomedical titanium is first subjected to anodic treatment followed by cathodic treatment in $\left(\mathrm{Ca}\left(\mathrm{NO}_{3}\right)_{2}\right)$ solution, following which, it is immersed into living body liquid, and alkali treatment, in which the biomedical titanium alloy is first immersed into $\mathrm{NaOH}$ solution and heated, following which, it is immersed into living body liquid. The whole surface of CP-Ti is covered with HAP, while the HAP is not formed on the surface of TNTZ. Therefore, which element is strongly inhibiting the formation of HAP should be made clear. Calcium hydroxyapatite $\left(\mathrm{Ca}_{10}\left[\mathrm{PO}_{4}\right]_{6} .5 \mathrm{H}_{2} \mathrm{O}\right)$ is a prominent calcium phosphate salts found in bone. But crystallographically hydroxyapatite (HA) is the dominant lattice structure of hard tissue. HA can be synthesized from biological skeletal carbonate by hydrothermal exchange as per the following reaction. [3]

$$
10 \mathrm{CaCO}_{3}+6\left(\mathrm{NH}_{2}\right)_{2}+2 \mathrm{H}_{2} \mathrm{O} \rightarrow \mathrm{Ca}_{10}\left(\mathrm{PO}_{4}\right)_{6}(\mathrm{OH})_{2}+6\left(\mathrm{NH}_{4}\right)_{2} \mathrm{CO}_{3}+4 \mathrm{H}_{2} \mathrm{CO}_{3}
$$

\section{Electrodeposition Method}

The electrolyte for deposition was prepared by dissolving the analytical grade $0.294 \mathrm{M}$ $\mathrm{CaCl}_{2} \cdot 2 \mathrm{H}_{2} \mathrm{O}, 0.042 \mathrm{M} \mathrm{SrCl} 2.6 \mathrm{H}_{2} \mathrm{O}, 0.042 \mathrm{M} \mathrm{MgCl} 2 \cdot 6 \mathrm{H}_{2} \mathrm{O}$ and $0.042 \mathrm{M} \mathrm{ZnCl}$ and $0.25 \mathrm{M}\left(\mathrm{NH}_{4}\right)_{2} \mathrm{HPO}_{4}$ in deionized water to produce the target $\left(\mathrm{Ca}_{2} \mathrm{X}\right) / \mathrm{P}$ ratio of 1.67 (where $\mathrm{X}{ }^{1 / 4} \mathrm{Sr}_{2} \mathrm{Mg}_{2} \mathrm{Zn}$ ). In the electrolyte solution, $2000 \mathrm{ppm}$ of $\mathrm{H}_{2} \mathrm{O}_{2}$ was added to reduce the $\mathrm{H}_{2}$ gas evolution. The electrolyte was de-aerated with $\mathrm{N}_{2}$ for 30 min during the deposition to minimize the formation of $\mathrm{CaCO}_{3}$ deposits. The $\mathrm{pH}$ of the electrolyte was adjusted to 4.5 using $\mathrm{NH}_{4} \mathrm{OH}$ or $\mathrm{HCl}$ and the temper-nature was maintained at $65^{\circ} \mathrm{C}$ using thermostat. To keep the uniform concentration of the electrolyte, the magnetic stirring was controlled at a speed of $180 \mathrm{rpm}$. [6]

\section{Plasma spray coating}

HA coatings were applied to the grit-blasted gauge sections of cylindrical Ti-6Al-4V coupons in thicknesses of 25,50,75, 100 and $150 \mathrm{~mm}$. All coatings were deposited using identical atmospheric plasma-spray (APS) parameters by American Plasma-Spray Ltd. Dayton, Ohio, USA. Evaluations of coating porosity were conducted independently each revealing $5 \%$ porosity by volume and cylindrical pore sizes ranging from 0.1 to $10 \mathrm{~mm}$.Mill-annealed Ti-6Al-4V extrusions machined to a minimum gauge diameter of $5.0 \mathrm{~mm}$ were used to construct unnotched fatigue specimens with a nominal $\mathrm{K}_{\mathrm{t}}$ of 1.00 . Each coupon was grit blasted with 80 -grit $\mathrm{Al}_{2} \mathrm{O}_{3}$ under a gas pressure of $0.689 \mathrm{MPa}$ (100 Psi). Tensile testing revealed yield and ultimate tensile strengths of 1014 and $1075 \mathrm{MPa}$, respectively, and fully reversed axial fatigue tests revealed the endurance limit after grit blasting to be $615 \mathrm{MPa}$.Cross-sections from the gauge sections of coupons in the as-machined, grit blasted, and grit blasted and sprayed conditions were prepared for metallographic examination. Each sample was ground and polished, then etched using an $85 \mathrm{H}_{2} \mathrm{O}: 10 \mathrm{HF}: 5 \mathrm{HNO}_{3}$ etchant before examination under a scanning electron micro-scope (SEM).Two additional specimens were given a full stress relieving treatment to alleviate the residual stresses generated during the grit blasting and extrusion processes. The treatment consisted of a 90 -hour hold at $400^{\circ} \mathrm{C}$ in air, with a subsequent furnace cool; the thin oxide layer evolved during the treatment was not removed before fatigue testing. [7] 


\subsection{Observations \& discussions}

\section{Structural Characteristics}

Hamdi and Ide-Ektessabi synthesized hydroxyapatite (HA) films on silicon substrate by vaporizing both $\mathrm{CaO}$ and $\mathrm{P}_{2} \mathrm{O}_{5}$ targets using electron beam heater and resistance heater, respectively and by simultaneous bombardment with Ar ion beams. The effects of ion beam current density on the phase evolution during the deposition process were investigated. From the XRD spectra strong tricalcium phosphate (TCP) phase together with the HA phase was observed when the ion beam is not used to assist the deposition. At ion beam current density of $180 \mathrm{~mA} / \mathrm{cm}^{2}$ a small TCP peak was observed, and at ion beam current density of $260 \mathrm{~mA} / \mathrm{cm}^{2}$ only the HA peaks were observed. The increase in $\mathrm{Ca} / \mathrm{P}$ ratio with increasing ion beam current density is mostly due to the high sputtering of $\mathrm{P}$ compared to that of Ca from the layer being coated. [8]

X-ray diffraction was employed to study the effect of mechanical alloying on Ti-HA composites. During MA process the original sharp diffraction lines of the Ti and HA gradually become broader and their intensity decreases with milling time. The peak broadening represents a reduction in the crystallite size and increase in the internal strain in the mechanically alloyed materials. After 44h of MA, the amorphous phase forms directly from the starting mixture, without formation of other phases. But differentiation between a "truly" amorphous, extremely fine grained or a material in which very small crystals are embedded in an amorphous matrix in so produced materials has not been easy on the basis of diffraction analysis. [9]

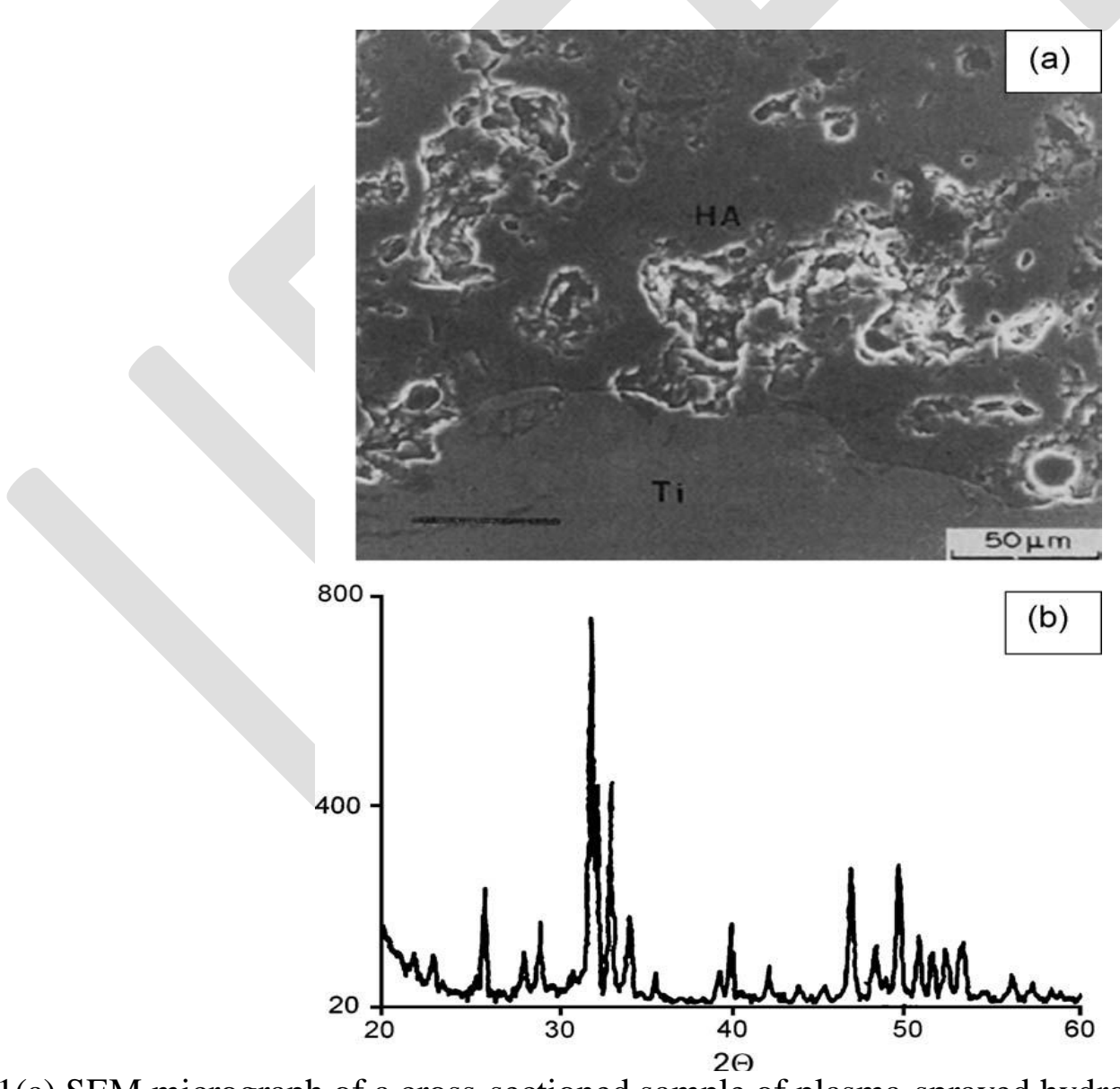

Fig. 1(a) SEM micrograph of a cross-sectioned sample of plasma-sprayed hydroxyapatite coating on the titanium: (HA) hydroxyapatite, (Ti) titanium and (b) an X-ray diffraction pattern taken from the surface of a plasma sprayed hydroxyapatite coating on titanium. [8] 


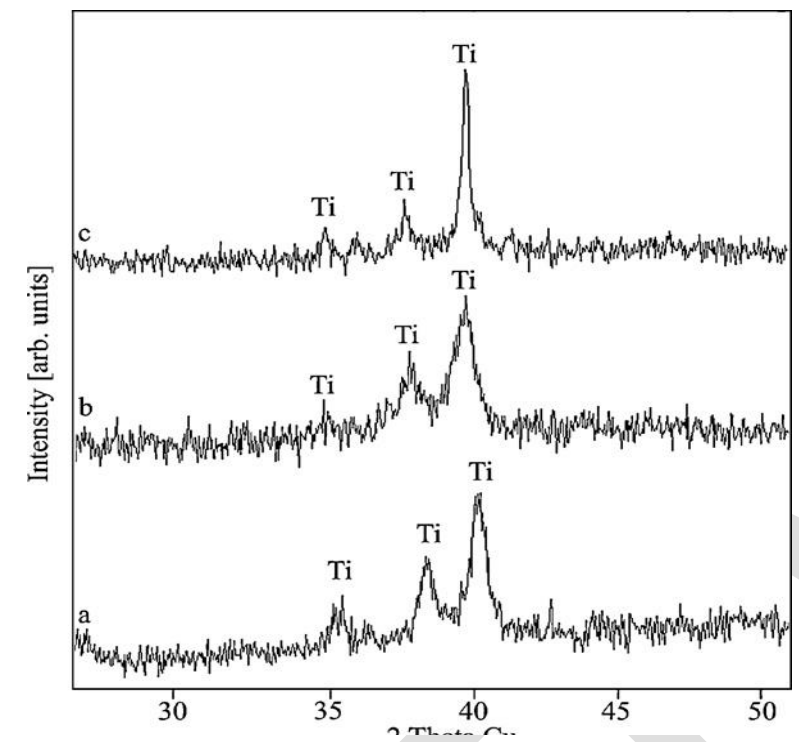

Fig. 2 XRD spectra of Ti and HA powders mechanically alloyed for $44 \mathrm{~h}$ and heat treated at $1150 \circ \mathrm{C}$ for $2 \mathrm{~h}$ under an argon atmosphere:

(a) $\mathrm{Ti}-3$ vol\% HA, (b) Ti-10 vol\% HA and (c) Ti-20 vol\% HA.

(b)

The milled titanium and hydroxyapatite powder's microstructure was analyzed by TEM. The sample milled for $44 \mathrm{~h}$ was mostly amorphous. Apart from prevailing amorphous phase, the milled powders contained small amount of fine-crystalline and crystalline phases. Lack of any sharp reflections in the XRD pattern suggests that the amount of the crystalline phase is very low and/or it forms during in TEM observation. During TEM studies, it has been found that the amorphous powders were unstable upon exposure to electron beam and underwent some crystallization. It can be seen that after $10 \mathrm{~h}$ of milling, the powder shows inhomogeneous size distribution. With the increase of milling time, the size of the mixed powders decreases gradually and the microstructure is more homogeneous. Formation of the bulk nanocomposites was achieved by cold uniaxial pressing and sintering of the amorphous materials. In all cases, XRD analysis of Ti-HA nanocomposites showed the presence of -Ti (hexagonal-type structure), but hydroxyapatite no longer exists. When 10 or 20 vol\% of hydroxyapatites is added to titanium the lattice constants of Ti increases, as manifested by a shift of the diffraction peaks of the $\left(\begin{array}{lll}1 & 0 & 0\end{array}\right),\left(\begin{array}{lll}0 & 0 & 2\end{array}\right)$ and $\left(\begin{array}{lll}1 & 0 & 1\end{array}\right)$ crystal planes of titanium towards smaller angles in comparison with pure microcrystalline titanium. Calcium has higher atomic diameter in comparison with titanium. [10]

Rabiei et al. [11] deposited functionally graded HA films on silicon substrate using a dual ion beam assisted deposition and simultaneous heat treatment process. shows the TEM cross-sectional view of the graded film. It was observed that grain size and crystallinity gradually decreased from the film/substrate interface to the film surface. The microstructure at the interface reveals very fine nanoscale crystalline columnar grains and at the top surface it is mostly amorphous. Micro scratch adhesion test and nanoindentation test on the deposited films were carried out to study the mechanical behavior of the coatings. The functionally Young's modulus (132 GPa) as compared to both sputter-deposited and sintered HA. Micro scratch adhesion test illustrated a better integrity of the graded film with no transverse cracking and delamination from the substrate. Several authors also studied the microstructure and morphological evolutions of the $\mathrm{Ca}-\mathrm{P}$ coatings on $\mathrm{Ti}$ base alloys synthesized using IBAD process.

Choi et al. [12] deposited HA films on Ti-6Al-4V by electron beam vaporization of pure HA target and simultaneous bombardment using a focused Ar ion beam on the metal substrate to assist deposition. The effect of Ar ion beam current on the bond strength and dissolution of the coating in a 
physiological solution is studied. The bond strength between the coating and the substrate increased with increasing current, whereas the dissolution rate in physiological solution decreased remarkably.

Zhao et al. [13] deposited two types of $\mathrm{Ca}-\mathrm{P}$ coatings, i.e. HA and porous tricalcium phosphate/hydroxyapatite (TCP/HA) on CP-Ti by IBAD. The biocompatibility of commercially pure titanium (CP-Ti), HA-coated CP-Ti, and porous TCP/HA-coated CP-Ti were investigated by culture of human gingival fibroblasts for different time periods. Cell attachment, cell spreading, collagen formation and the number of focal adhesion plaque was predominant with TCP/HA coated substrate as compared to $\mathrm{Ti}$ and HA coated substrate. This improved biocompatibility of TCP/ HA coated substrate is attributed to the lower $\mathrm{Ca} / \mathrm{P}$ ratio.

The SEM micrographs of the electrodeposited HAP and $\mathrm{Cu}$-doped HAP are observed. SEM results provide the direct information about the size and shape of the deposited coatings. The results suggested that the substitution of $\mathrm{Cu}$ in HAP increased the density, i.e., a relatively lower porosity than HAP coating. The chemical composition consisted of $\mathrm{Ca}, \mathrm{P}, \mathrm{Ti}$, and $\mathrm{O}$. The $\mathrm{Ca} / \mathrm{P}$ ratio was around 1.13, which was lower than 1.67 (the mole ratio of $\mathrm{Ca}$ to $\mathrm{P}$ of stoichiometric HAP). The $\mathrm{Ca} / \mathrm{P}$ and $\mathrm{Cu} / \mathrm{P}$ molar ratios were 1.04 and 0.026 , respectively. The above results suggest that $\mathrm{CuHAP}$ was $\mathrm{Ca}$ deficient with a few $\mathrm{Cu}$ substitutions (about $0.80 \mathrm{wt} \%$ ). EDS elemental mapping demonstrated uniform distribution of $\mathrm{Cu}, \mathrm{Ca}, \mathrm{P}, \mathrm{Ti}$, and $\mathrm{O}$ on the structure surface. Evidently, the coating maintained a uniform and evenly distributed $\mathrm{Cu}$ across the entire surface. [14]

\section{Compositional analysis}

Chemical composition of a biomaterial surface can be characterized using X-ray photo electron spectroscopy (XPS), auger electron spectroscopy (AES), Fourier transformation infrared (FTIR) spectroscopy, X-ray diffraction (XRD), and secondary ion mass spectroscopy (SIMS). XPS is widely used to determine the elemental composition of solid surfaces (except $\mathrm{H}$ and He). AES can be used for determining both the chemical composition of a solid surface and mapping the spatial distribution of the surface constituents and obtain a depth profile of these constituents into the bulk of the material. FTIR holds the capability for chemical analysis of solids, liquids and gasses. It is based on the fact that every molecule has a vibrational spectrum, which is a unique physical property and is a characteristic of the molecule [15]. SIMS is used to determine the surface and near-surface composition in a wide range of solid materials. It is based on the principle that bombardment of a material with a high-energy (1-30 keV) ion beam results in the ejection or sputtering of atoms from the material. XRD is a non-destructive technique that provides detailed information about the chemical composition and crystallographic structure of natural and manufactured materials. The phases of the spark-plasma-sintered composites, as determined by XRD analysis, contained a-Ti, $\mathrm{TiC}$, and $\mathrm{CaO}$ for the composites with $10 \%$ and $20 \% \mathrm{HA}$, and additional phases of $\mathrm{CaTiO}_{3}$ and $\mathrm{TiN}$ formed on the composites with $30 \%$ HA [17]. No HA phase was observed. HA decomposition during SPS is unavoidable owing to the high-temperature process and the presence of $\mathrm{Ti}$ that catalyses such decomposition. In general, $\mathrm{Ca}$ concentration increased with HA concentration. The intensity of the $\mathrm{O}$ signal was high at the start of the measurement but decreased significantly at about $25 \mathrm{~s}$. After sputtering for $50 \mathrm{~s}$, the intensity of the $\mathrm{O}$ signal became stable at nearly zero, which indicated the presence of metal, as confirmed from the Ti profile that showed a stable concentration. The $\mathrm{Ti}$ and $\mathrm{Ca}$ profiles of the 10\%-HA-containing composite were lower than those of the other composites possibly owing to defects in the analysis area. The intensities of $\mathrm{Ca}$ and $\mathrm{P}$ increased with increasing HA concentration. The $\mathrm{Ca}$ profile of Ti-30HA-MA4 reached a stable intensity immediately after the measurement started, indicating $\mathrm{Ca}$ incorporation in the oxide film, possibly corresponding to the hydrated $\mathrm{CaO}$ phase. Phosphorus, which was not detected by XRD analysis, was successfully analysed both qualitatively and quantitatively by GDOES and EDX spectroscopy, respectively. It is probably present in the amorphous phase. Calcium might exist in the amorphous or crystalline phase, as was previously detected by XRD analysis [16]. 


\section{Surface microstructure}

The pure Ti surface exhibited a smooth solid structure similarly to the polished surface of $\mathrm{CP}-\mathrm{Ti}$. There was no significant difference between the surface structures of the pure Ti specimens milled for 4 and $8 \mathrm{~h}$. Ti- (10-30) HA composites also showed similar compact structures, except that few craterlike defects were observed randomly on their surface owing to the release of some ceramic particles during polishing. Particulate residue could sometimes be observed on the surface. Many large defects were observed only on the Ti-10HA-MA4 surface. They were about $50 \mathrm{~lm}$ long and 30 ln deep. The EDX spectra of the circular spot gave only $\mathrm{Ca}$ and $\mathrm{O}$ peaks corresponding to the $\mathrm{CaO}$ phase that was probably hydrated upon humidity or water exposure [18].

\section{Corrosion behavior}

The implants are placed in a corrosive environment which includes blood and other constituents of the body fluid which encompass several constituents like water, sodium, chlorine, proteins, plasma, amino acids along with mucin in the case of saliva [19]. The aqueous medium in the human body consists of various anions such as chloride, phosphate, and bicarbonate ions, cations like $\mathrm{Na}^{+}$, $\mathrm{K}^{+}, \mathrm{Ca}^{2+}, \mathrm{Mg}^{2+}$ etc., organic substances of low-molecular-weight species as well as relatively high molecular- weight polymeric components, and dissolved oxygen [20]. Changes in the $\mathrm{pH}$ values also influence the corrosion. Though, the $\mathrm{pH}$ value of the human body is normally maintained at 7.0, this value changes from 3 to 9 due to several causes such as accidents, imbalance in the biological system due to diseases, infections and other factors and after surgery the $\mathrm{pH}$ value near the implant varies typically from 5.3 to 5.6. It has been well accepted that the tolerable corrosion rate for metallic implant systems should be about $2.5 \times 10-4 \mathrm{~mm} / \mathrm{yr}$, or $0.01 \mathrm{mils} / \mathrm{yr}$ [21]. The most common forms of corrosion that occur are uniform corrosion, intergranular, galvanic and stress corrosion cracking, pitting and fatigue corrosion. The study of $\mathrm{Yu}$ et al. reveals that the nitrogen ion implantation and heat treatment procedures enhance the corrosion fatigue of Ti-6Al-4V alloy [57]. In spite of the fact that there is no histological evidence to show the slow release of metallic ions due to corrosion, the discoloration of the surrounding tissue and the foreign body reactions clearly indicate that this is due to corrosion of implants. It is found that this dissolution of metal ions can be reduced by suitable biocompatible inorganic coatings, such as hydroxy-apatite (HAP) coating with some binders, and this can lead to delay in corrosion and wear and also minimize the loosening of implants from bone [22].

\section{Electrochemical Analysis}

In this study, potentiodynamic polarization and electrochemical impedance measurements (EIS) were carried out in simulated body fluid. The ion concentrations and $\mathrm{pH}$ of the simulated body fluid must be nearly equal to that of human blood plasma. The chemical composition and preparation of the simulated body fluid is adopted from Kokubo's procedure [23]. Potentiodynamic polarization studies were performed in a potential range of $0.2 \mathrm{eV}$ vs SCE at a scan rate of $0.001 \mathrm{Vs}^{-1}$. The EIS measurements were carried out with the frequency ranging from $10^{-2}-10^{5} \mathrm{~Hz}$. Nyquist and Bode plots were obtained after the specimens were immersed in the simulated body fluid for $1 \mathrm{~h}$. The potentiodynamic polarization and EIS were repeated at least three times in order to obtain the average test results.

The open-circuit potential of the polished specimens was measured for $1000 \mathrm{~min}$ in $0.9 \mathrm{wt} . \%$ $\mathrm{NaCl}$ solution. All the curves demonstrated similar trends of an immediate increase in potential from the corrosion potential and tended to stabilize at higher potentials, indicating surface passivation. The potential for the $\mathrm{Ti}-(0-10) \mathrm{HA}$ composites stabilized in the range between 0.03 and $0.1 \mathrm{~V}$ Increasing HA concentration to $20-30 \%$ shifted the curve to a lower potential with the steady state potential. The variation in the stable potential for either Ti- (0-10) HA or Ti- (20-30) HA was within the range of experimental reproducibility. The h-alloyed composites containing 0-30\% HA in 0.9 wt.\% $\mathrm{NaCl}$ solution at $36.5^{\circ} \mathrm{C}[24]$. 
The peak became larger but the curve shifted to a slightly lower potential and a higher current when a higher scan rate of $10 \mathrm{mV} / \mathrm{s}$ was used. Oppositely, lower scan rates of 1 and $0.5 \mathrm{mV} / \mathrm{s}$ tended to flatten the curves as the second oxidation peak disappeared in all cases including that of pure Ti and the whole curves shifted to a nobler potential and a lower current. Therefore, a medium scan rate of $5 \mathrm{mV} / \mathrm{s}$ was used in this work to observe the two characteristic peaks of Ti in most of the curves. However, the corrosion current density determined from the polarization curve is meant only for comparison, and is unlikely to be in the steady state at the scan rate used $(5 \mathrm{mV} / \mathrm{s})$. The corrosion potentials of both 4 and $8 \mathrm{~h}$ alloyed $\mathrm{Ti}-10 \mathrm{HA}$ composites were on the same order of $0.3 \mathrm{~V} \mathrm{Ag} / \mathrm{AgCl}$ [25].

The anodic polarization curve for Ti-10HA-MA4 also shifted to a higher current than those for pure $\mathrm{Ti}$ and the 8-h-alloyed composite. Increasing $\mathrm{HA}$ concentration to $20 \%$ and $30 \%$ in the composites respectively decreased the corrosion potential gradually to 0.63 and $0.71 \mathrm{~V} \mathrm{Ag} / \mathrm{AgCl}$ for the $8 \mathrm{~h}$-alloyed composites and further to 0.75 and $0.95 \mathrm{~V} \mathrm{Ag} / \mathrm{AgCl}$ for the 4-h-alloyed composites. The anodic polarization curve for the Ti-30HA composite shifted at a nearly tenfold higher current than that for the Ti-20HA composite. The anodic currents of $\mathrm{Ti}-20 \mathrm{HA}$ and $\mathrm{Ti}-30 \mathrm{HA}$ above the corrosion potential were consistently higher by about one and two orders of magnitude, respectively, than that of $\mathrm{Ti}-(0-10)$ HA. Thus, the 8-h-milled composites tended to show a higher corrosion potential and a slightly lower anodic current than the 4-h-milled composites [26].

The potentiodynamic curves were generally highly reproducible on the replicate specimens. The curve for Ti-10HA-MA4, which had many large craterlike defects, was also reproducible, but only up to a potential of $0.1 \mathrm{~V}$. To study corrosion behavior as a function of time, potentiostatic test was performed on the Ti-HA composites at a potential of $0.5 \mathrm{~V} \mathrm{Ag} / \mathrm{AgCl}$, which was in the region where the specimens showed a passivation tendency in the polarization curve. The current density for Ti- $(0-10) \mathrm{HA}$ decreased, reaching $10^{-7} \mathrm{~A} / \mathrm{cm}^{2}$ after a $40-$ min test, indicating passivation. A similar behavior was demonstrated by CP-Ti but at a slightly lower current. Increasing HA content to $20 \%$ stabilized current at a higher current density of $6 * 10^{6} \mathrm{~A} / \mathrm{cm}^{2}$ for the 8-halloyed composite and further at $2 \times 10^{5} \mathrm{~A} / \mathrm{cm}^{2}$ for the 4-alloyed one. The $30 \% \mathrm{HA}$ composite showed the highest plateau current density at $3 \times 10^{5} \mathrm{~A} / \mathrm{cm}^{2}$ for the 4-h-alloyed and $6 * 10^{5} \mathrm{~A} / \mathrm{cm}^{2}$ for the 8 h-alloyed; however, the time to reach the stable current was faster for the latter composites than for the former [27].

\section{Antimicrobial study}

The antimicrobial activity of the samples was tested against two bacterial strains S. aureus and E. coli by agar diffusion method. The inoculums of all microorganisms were prepared from fresh overnight broth cultures (Trypton soy broth with $0.6 \%$ yeast extract) that were incubated at $37{ }^{\circ} \mathrm{C}$. The resulting broth cultures were used for the test. The diffusion technique was carried out by pouring agar into petri dishes to form $4 \mathrm{~mm}$ thick layers and adding dense inoculum of the tested microorganisms in order to obtain semiconfluent growth. Petri plates were dried for $10 \mathrm{~min}$ in air. Then, the discs were prepared using Whatmann filter paper, immersed into different samples, placed on petri dishes and incubated for $24 \mathrm{~h}$ at $37^{\circ} \mathrm{C}$. The result of inhibition was calculated by measuring the width of the inhibited zone [28,29].

\section{Cell viability Study}

MG63 osteoblast-like cells from human osteosarcoma were cultured in standard culture medium which consisted of a minimal essential medium, supplemented with $10 \%$ fetal bovine serum (FBS), and 1\% non-essential amino acids (GIBCO). The medium was renewed every 2 days and the cultures were maintained in a humidified atmosphere with $5 \% \mathrm{CO}_{2}$, at $37^{\circ} \mathrm{C}$. The confluent osteoblast cultures were detached from the culture flask by incubation with $0.1 \%$ trypsin and $0.1 \%$ ethylene diamine tetra acetic acid (EDTA) for $5 \mathrm{~min}$ [30]. The growth and viability of cells colonizing the samples were evaluated by measuring the mitochondrial dehydrogenase activity using a modified MTT (3-(4,5-dimetyl-2-tiazolyl)-2,5-diphenyl-2Htetrazolium bromide) assay. To 
determine the cytotoxicity of MHAP at different conditions, MG63 cells were seeded in 12-well plates at 104 cells $/ \mathrm{ml}$ in a humidified $5 \% \mathrm{CO}_{2}$ atmosphere. After $24 \mathrm{~h}$ of incubation, MTT solution in $1 \mathrm{ml}$ serum free medium was added and incubated for $4 \mathrm{~h}$ at $37^{\circ} \mathrm{C}$ in a humidified $5 \% \mathrm{CO}_{2}$ atmosphere. The solution was then removed, added dimethyl sulfoxide, and the plate was shaken for $15 \mathrm{~min}$ before measuring absorbance at $570 \mathrm{~nm}$ (the reference value was $690 \mathrm{~nm}$ ) on an ELISA microplate reader and then $\%$ cell viability was calculated [31].

\section{Cell adhesion study}

The M-HAP coatings on Ti-6Al-4V alloy deposited at prolonged pulse on and off time were used as the samples for cell adhesion experiment. The seeded test sample was incubated in a $\mathrm{CO}_{2}$ incubator with the standard culture condition. The culture medium was aspirated after 2days interval and fresh culture medium was added into each well. After the stipulated time period (36 - $48 \mathrm{~h})$, the samples were washed twice with phosphate buffer saline ( $\mathrm{pH} 7.4)$. For cell morphology observation, the HOS MG63 cells attached to the samples were fixed with $2 \%$ glutaraldehyde for $1 \mathrm{~h}$ at room temperature followed by dehydration with a series of ethanol water solution for 10 min twice. Then $0.5 \mathrm{ml}$ hexamethyl disilazane was added to each well to preserve the original morphology of the cells [32].

\section{In vitro bioactivity analysis}

Some specimens were selected for bioactivity test in SBF including pure $\mathrm{Ti}$ as well as $\mathrm{Ti}-$ 30HA-MA4 and Ti-10HA-MA8, corresponding to the composites with the highest and lowest $\mathrm{Ca} / \mathrm{P}$ ratios, respectively. All of the pure Ti specimens showed no growth of HA layers or particles after immersion for 2 days or 1 week. Meanwhile, few bright particles were observed randomly on the surface of Ti-30HA-MA4 after a 2-day immersion. The EDX point analysis of the particles showed strong intensities of $\mathrm{Ca}$ and $\mathrm{P}$ with a $\mathrm{Ca} / \mathrm{P}$ ratio of 1.22 , which was lower than the ratio for $\mathrm{HA}$. The $\mathrm{Ca} / \mathrm{P}$ ratio was 1.33 , which was relatively higher than that of the polished surface $(0.70)$. A similar Nano-HA layer was also grown on the Ti-10HA-MA8 surface after an identical test was performed. Longer immersion in SBF for 5days and 1week was also examined for Ti-10HA-MA8 and Ti30HA-MA4. The size and density of HA particles increased with exposure time. The Nano globular layer probably thickened. However, the FE-SEM instrument used in this work could not differentiate between the thicknesses of the layers grown for 2 days and 1 week because the layers were very thin, i.e., on the order of 5-10 nm [33].

\section{In vitro cytotoxicity studies}

SEM images revealed differences in cell density and spreading patterns among the MC3T3E1 cells grown on the HAP-coated and non-coated Ti substrates after $24 \mathrm{~h}$. The results indicated that the cells spread well onto all the samples and exhibit active cytoskeletal extension. This appearance suggested good cell viability on the CuHAP and HAP films. The cell viability of $0.8 \mathrm{wt} \% \mathrm{Cu}-\mathrm{HAP}$ showed cell morphology similar to the HAP which declares that this does not show any toxic nature [34]. Therefore, it could be concluded that $\mathrm{Cu}$ (II) does not affect the cell morphology of MC3T3-E1 cells. In the present work, the cytotoxicity of $\mathrm{Cu}$-HAP coating was evaluated by the MTT test using the MC3T3-E1 as a cell model. From the MTT tests, it is distinct that the number of cells proliferated with time for all samples. After 1day of culturing, the cell number did not significantly differ between the pure Ti and the coated specimens (Cu-HAP and HAP coatings), which was in agreement with the cell adhesion results. During the following two periods ( 3 and $5 \mathrm{~d}$ ), the cell numbers on bare Ti were significantly lower (P\0.05) than those on the coated specimens, indicating that the $\mathrm{Cu}-\mathrm{HAP}$ and HAP coatings had higher cytocompatibility than the bare Ti. However, there was a slight trend of increased proliferation activity in a $\mathrm{Cu}$-content-dependent manner after culturing for $5 \mathrm{~d}$. These results showed that the obtained HAP coating doped with the lower content of $\mathrm{Cu}^{2+}(0.80 \mathrm{wt} \%)$ showed good cytocompatibility and had no noticeable cytotoxicity toward osteoblast cells, and was 
favourable for implant applications. But, such concentration of $\mathrm{Cu}$ must also instil an antibacterial effect by restraining the growth of bacteria to prevent the microbial infections when used as in vivo implants. It is critical that the target coating surface does not release any toxic ions or compounds that could injure the cells involved in osteogenesis. In this case, HAP, the main component of the hard tissue, releases minimal toxicity to the cells of the guest organism. $\mathrm{Cu}$ ions may be useful in vitro to promote angiogenesis prior to implantation; therefore, stimulating the survival of cells is incorporated in tissue engineering equipment [35 - 37]. $\mathrm{Cu}$ has been shown to reduce osteogenic differentiation of mesenchymal stem cells after 14 days [38].

\section{CONCLUSION}

The application of titanium and its alloys in biomedicalapplications is rapidly increasing. Therefore, further developmentsof titanium alloys appropriate for biomedicalapplications are strongly desired. For these applications,titanium alloys that comprise nontoxic and allergyfreeelements should be developed. Further, these alloys shouldexhibit functionalities such as super elasticity and shapememory effect. In addition, mechanical performance parameterssuch as strength, ductility, fatigue strength, frettingfatigue strength, and wear resistance are very importantfactors for biomedical applications. Biomaterials with appropriate mechanical properties, surface chemistry and surface topography are in a great demand for enhancing cell attachment, cell growth and tissue formation at such defect sites.

\section{REFERENCES}

1. Hyeoung Ho Park, Song Park, Kyeong Seon Kimb, Woo Yong Jeon, "Bioactive and electrochemical characterization of $\mathrm{TiO} 2$ nanotubes on titanium via anodic oxidation" Electrochimica Acta 55 (2010) 6109-6114.

2. Mitsuo Niinomi, "Biologically and Mechanically Biocompatible Titanium Alloys", 2008 The Japan Institute of Light Metals.

3. J.R. Davis, "Hand Book of Materials for Medical Devices", 1st ed., ASM International, 2003.

4. Sameer R. Paital, Narendra B. Dahotre, "Calcium phosphate coatings for bio-implant applications: Materials, performance factors, and methodologies", Materials Science and Engineering R 66 (2009).

5. Long M, Rack HJ, "Titanium alloys in total joint replacement- a materials science perspective", Biomaterials 1998; 19: 1621-39.

6. L. Bolzoni, T. Weissgaerber, B. Kieback, E.M. Ruiz-Navas, E. Gordo, J. Mech. Behav. "Mechanical behaviour of pressed and sintered $\mathrm{CP} \mathrm{Ti}$ and $\mathrm{Ti}-6 \mathrm{Al}-7 \mathrm{Nb}$ alloy obtained from master alloy addition powder", Biomed. Mater. 20 (2013) 149-161.

7. J. M_alek, F. Hnilica, J. Vesely, B. Smola, S. Bart_akov_a, J. Vanek, "The influence of chemical composition and thermo-mechanical treatment on Ti-Nb-Ta-Zr alloys", Mater. Des. 35 (2012) $731 \mathrm{e} 740$.

8. Anawati, Hiroaki Tanigawa, Hidetaka Asoh, Takuya Ohno, Masahiro Kubota, Sachiko Ono, "Electrochemical corrosion and bioactivity of titanium-hydroxyapatite composites prepared by spark plasma sintering”, Corrosion Science 70 (2013) 212-220. 
9. M. Hamdi, A. Ide-Ektessabi, "Preparation of hydroxyapatite layer by ion beam assisted simultaneous vapor deposition” Surface and Coatings Technology 163-164 (2003) 362-367.

10. Y.H. Huang, A.V. Xiropaidis, R.G. Sorensen, J.M. Albandar, J. Hall, U.M.E. Wikesjö, "Bone formation at titanium porous oxide (TiUnite) oral implants in type IV bone", Clin. Oral Impl. Res. 16 (2005) 105.

11. A. Rabiei, B. Thomas, C. Jin, R. Narayan, J. Cuomo, Y. Yang, J.L. Ong, "A study on functionally graded HA coatings processed using ion beam assisted deposition with in situ heat treatment", Surface and Coatings Technology 200 (2006) 6111-6116.

12. Jae-Man Choi, Hyoun-Ee Kim, In-Seop Lee, "Improvement of fibroblast adherence to titanium surface by calcium phosphate coating formed with IBAD” - Biomaterials 21 (2000) 469-473.

13. B.H Zhao, S Lee, BaiF, Z Cui, H LFeng, "Antibacterial efficacy, corrosion resistance, and cytotoxicity studies of copper substituted carbonated hydroxyapatite coating on titanium substrate",Journal of Materials Science , February 2015, pp 1688-1700.

14. Li Y, Ho J, Ooi CP, “Antibacterial efficacy and cytotoxicity studies of copper(II) and titanium(IV) substituted hydroxyapatite nanoparticles"-2010, Mater Sci Eng. C 30:1137-1144.

15. Batra U, Kapoor S, Sharma S, "Influence of magnesium ion substitution on structural and thermal behavior of Nano dimensional hydroxyapatite", J Mater Eng Perform 22:1798-1806.

16. Hu W, Ma J, Wang JG, Zhang SM, "Fine structure study on low concentration zinc substituted hydroxyapatite nanoparticles" (2012) Mater Sci Eng C 32:2404-2410.

17. Papargyri, S. A, Tsipas, D., Stergioudis, G., Chlopek, J. "Production of titanium and hydroxyapatite composite biomaterial for use as biomedical implant by mechanical alloying process", Mater. Sci. Eng. C 48 (2015) 11e20.

18. Huinan Liu' HilalYazici' Celaletdin, ErgunThomas J.WebsterHakanBermek, "An in vitro evaluation of the $\mathrm{Ca} / \mathrm{P}$ ratio for the cytocompatibility of nano-to-micron particulate calcium phosphates for bone regeneration", 2008.

19. Richard C, Kowandy C, Landoulsi J, Geetha M, Ramasawmy H. "Corrosion and wear behavior of thermally sprayed nano ceramic coatings on commercially pure Titanium and Ti-13Nb-13Zr.", Int. J Refractory Metals Hard Mater 2010; 28(1): 115-23.

20. T.M. Sridhar, U. Kamachi Mudali, M. Subbaiyan, "Preparation and characterisation of electrophoretically deposited hydroxyapatite coatings on type $316 \mathrm{~L}$ stainless steel", Corrosion Science 45 (2003) 237-252.

21. Yu Mi Lee, Eun Jung Lee, Sung Tae Yee, Byung II Kim, Eun Sang Choe, Hyun Wook Cho, "In vivo and in vitro response to electrochemically anodized Ti-6Al-4V alloy"Journal of Materials Science: Materials in Medicine 19 (2008) 1851-1859.

22. Biomedical Implants: Corrosion and its Prevention - A Review Geetha Manivasagam , Durgalakshmi Dhinasekaran and Asokamani Rajamanickam, Recent Patents on Corrosion Science, 2010, 2, 40-54 
23. T. Seshacharyulu, S.C. Medeiros, W.G. Frazier, Y.V.R.K. Prasad, "Hot working of commercial Ti-6Al-4V with an equiaxed $\alpha-\beta$ microstructure: materials modeling considerations" - Materials Science and Engineering A 284 (2000) 184-194.

24. X. Cui, H. Kim, M. Kawashita, L. Wang, T. Xiong, T. Kokubo, T. Nakamura, Dent. "Preparation of bioactive titania films on titanium metal via anodic oxidation"

Materials 25 (2009) 80.

25. Q. Ma, M. Li, Z. Hu, Q. Chen, W. Hu, Mater. Lett, "Enhancement of the bioactivity of titanium oxide nanotubes by precalcification" - 62 (2008) 3035.

26. Y.L. Hao, S.J. Li, S.Y. Sun, C.Y. Zheng, R. Yang, "Elastic deformation behaviour of Ti-24Nb-4Zr-7.9Sn for biomedical applications", Acta Biomater. 3 (2007) 277e286.

27. M. Abdel-Hady Gepreel, M. Niinomi, "Biocompatibility of Ti-alloys for longterm implantation", J. Mech. Behav. Biomed. Mater 20 (2013) 407e415.

28. Foldbjerg R, Olesen P, Hougaard M, Dang DA, Hoffmann HJ, "PVP-coated silver nanoparticles and silver ions induce reactive oxygen species, apoptosis and necrosis in THP-1 monocytes", (2009) Toxicol Lett 190(28):156-162

29. J.H. Li, X.Y. Liu, Y.Q. Qiao, H.Q. Zhu, J.B. Li, T. Cui, C.X. Ding, “The fabrication of Agcontaining hierarchical micro/nano-structure on titanium and its antibacterial activity", RSC Adv. 3 (2013) 11214-11225.

30. Busscher HJ, Ploeg RJ, van der Mei HC, "Biofilms and biomaterials; mechanisms of medical device related infections", Biomaterials 2009; 30:4047e8.

31. Siemon U, Bahnemann D, Testa JJ, Rodríguez D, Litter MI, Bruno N. “ Heterogeneous photocatalytic reactions comparing $\mathrm{TiO}_{2}$ and $\mathrm{Pt} / \mathrm{TiO}_{2}$ " -Journal of Photochemistry and Photobiology A: Chemistry 31 May 2002.

32. J.I. Rosales-Leal, M.A. Rodríguez-Valverde, G. Mazzaglia, P.J. Ram_on-Torregrosa, L. DíazRodríguez, O. García-Martínez, "Effect of roughness, wettability and morphology of engineered titanium surfaces on osteoblast-like cell adhesion", Colloids Surf. A Physicochem. Eng. Aspects 365 (2010) 222.

33. Fuller TA, Wysk RA, Charumani C, Kennett M, Sebastiennelli WJ, Abrahams R, Royer P (2010) "Developing an engineered antimicrobial/prophylactic system using electrically activated bactericidal metals", J Mater Sci Mater Med 21(7):2103-2114.

34. Guo YJ, Long T, Chen W, Ning CQ, Zhu ZA, Guo YP "Bactericidal property and biocompatibility of gentamicin-loaded mesoporous carbonated hydroxyapatite microspheres", (2013) Material Science Engg. C 33:3583-3591.

35. Costa DO, Prowse PDH, Chrones T, Sims SM, Hamilton DW, Rizkalla A, "The differential regulation of osteoblast and osteoclast activity by surface topography of hydroxyapatite coatings", (2013). Biomaterials 34:7215-7226. 
36. Li CF, Ge XL, Zhao JY, Li GC, Bai JH, Du QY, "Preparation and characterization of novel hydroxyapatite/copper assemblies with well-defined morphologies", (2014) Solid State Sci 29:66-74.

37. Yong Huang, Xuejiao Zhang, Ranlin Zhao, Huanhuan Mao, Yajing Yan, Xiaofeng Pang, "Antibacterial efficacy, corrosion resistance, and cytotoxicity studies of copper-substituted carbonated hydroxyapatite coating on titanium substrate", J Mater Sci (2015) 50:1688-1700.

38. Huang Y, Ding QQ, Han SG, Yan YJ, Pang XF, "Characterization, corrosion resistance and in vitro bioactivity of manganese-doped hydroxyapatite films electrodeposited on titanium (2014), J Mater Sci Mater Med 24:1853-1864. 